\title{
Hubungan Derajat Ketoasidosis Diabetik dengan Kadar Kalium pada Pasien Anak di Rumah Sakit Dr. Hasan Sadikin Periode Tahun 2014-2019
}

Faisal, Aliva Tamara Adelaine Mulyadi, Titing Nurhayati

Departemen Ilmu Kesehatan Anak Fakultas Kedokteran Universitas Padjadjaran/RSUP Dr. Hasan Sadikin, Bandung

Latar belakang. Ketoasidosis diabetik (KAD) seringkali menjadi komplikasi penyakit DM tipe-1 dan merupakan kondisi gawat darurat yang dapat menyebabkan morbiditas dan mortalitas yang tinggi pada anak. Gangguan elektrolit termasuk kadar kalium dapat terjadi pada pasien KAD. Perubahan kadar kalium dapat terjadi karena peningkatan kadar kalium akibat defisiensi insulin, asidosis, dan hiperglikemia. Sementara penurunan kadar kalium berakibat diuresis osmotik, asupan makanan berkurang, dan muntah. Abnormalitas kadar kalium dapat menyebabkan peningkatan morbiditas dan mortalitas. Pemeriksaan kadar elektrolit termasuk kalium penting dilakukan dalam diagnosis KAD.

Tujuan. Mengetahui hubungan antara derajat KAD dan kadar kalium pada pasien anak di RSUP Dr. Hasan Sadikin.

Metode. Penelitian dilakukan pada September - November 2019 dengan rancangan studi analitik potong lintang menggunakan data sekunder yang diperoleh dari data rekam medis pasien KAD anak di RSUP Dr. Hasan Sadikin Bandung selama periode Desember 2014 - Oktober 2019. Data karakteristik umum dan klinis pasien dikumpulkan dan dilakukan uji korelasi Spearman untuk melihat hubungan antara derajat KAD dan kadar kalium dengan kemaknaan $\mathrm{p}<0,05$.

Hasil. Penelitian ini melibatkan 35 pasien KAD anak dengan total 39 episode. Enam (15,39\%) pasien mengalami KAD derajat ringan, $13(33,33 \%)$ sedang, dan 20 (51,28\%) berat. Pada pemeriksaan kadar kalium pasien didapatkan 9 (23,08\%) dengan hipokalemia, 21 $(53,84 \%)$ normokalemia, dan $9(23,08 \%)$ hiperkalemia. Dari hasil analisis Spearman didapatkan korelasi yang lemah antara derajat KAD dan kadar kalium (koefisien korelasi Spearman $(r)=0,471$, nilai $\mathrm{p}=0,002)$.

Kesimpulan. Derajat KAD dengan kalium belum bisa dihubungkan mengingat sampel yang belum memadai dan hasil uji statistik yang masih lemah. Sari Pediatri 2020;22(2):71-5

Kata kunci: ketoasidosis diabetik, kalium, DM tipe-1, anak

\section{Correlation of Diabetic Ketoacidosis Severity and Potassium Levels in Pediatric Patients at Hasan Sadikin General Hospital in 2014-2019}

Faisal, Aliva Tamara Adelaine Mulyadi, Titing Nurhayati

Background. Diabetic ketoacidosis (DKA) often complicates pediatric patients with type 1 diabetes. DKA is an emergency condition and can cause high morbidity and mortality in children. Disturbances in electrolyte levels including potassium can occur in DKA patients. Alteration of potassium levels in DKA patients can occur because of several things: insulin deficiency, acidosis, and hyperglycemia can cause an increase in potassium level; osmotic diuresis, decrease of food intake, and vomiting can cause a decrease in potassium level. Potassium level abnormality can cause morbidity and mortality in DKA. Electrolyte levels testing including potassium level is important in diagnosis of DKA.

Objective. To determine the correlation between the severity of DKA and potassium levels in pediatric patients at Hasan Sadikin General Hospital, Bandung.

Methods. This study was conducted in September - November 2019 with cross-sectional analytic study design and uses secondary data from Hasan Sadikin General Hospital medical record of pediatric DKA patients in December 2014 - October 2019 period. Data on general and clinical characteristics of patients were collected and Spearman analytical correlation test were performed to see the relationship between the severity of DKA and potassium level with significance of $\mathrm{p}<0,05$.

Result. This study involves 35 pediatric DKA patients with a total of 39 DKA episodes. A total of 6 (15.39\%) patients experienced mild DKA, 13 (33.33\%) moderate, and 20 (51.28\%) severe with potassium levels as many as 9 patients (23.08\%) with hypokalemia, $21(53.84 \%)$ normokalemia, and $9(23.08 \%)$ hyperkalemia. The Spearman analysis gave a result of weak correlation between the severity of DKA and potassium level (Spearman's correlation coefficient $(r)=0.471$, p value $=0.002$ ).

Conclusion. The correlation between severity of DKA and potassium levels cannot be established yet according to inadequate sample size and statistical test. Sari Pediatri 2020;22(2): 71-5

Keywords: diabetic ketoacidosis, potassium, type 1 diabetes, children

Alamat korespondensi: Faisal. Departemen/Kelompok Staf Medis Ilmu Kesehatan Anak Fakultas Kedokteran Universitas Padjadjaran/Rumah Sakit dr. Hasan Sadikin Jl. Pasteur no. 38 Bandung 40161. Email: faisal@unpad.ac.id 
K etoasidosis diabetik (KAD) merupakan salah satu komplikasi akut dari penyakit diabetes melitus (DM), terutama pada DM tipe- $1 .{ }^{1}$ Kejadian KAD karena adanya defisiensi hormon insulin dan aksi hormon counterregulatory, terutama glukagon, yang tidak terhambat. Kriteria biokimia berupa hiperglikemia, ketosis, dan asidosis metabolik. Derajat KAD dapat dibagi menjadi ringan, sedang, dan berat berdasarkan derajat keparahan asidosis. ${ }^{2,3}$

Kegawatdaruratan KAD dapat menyebabkan komplikasi lanjutan yang fatal, dengan angka kematian 0,5 hingga 7\%. ${ }^{1,4}$ Faktor-faktor, seperti sulitnya mengenali tanda-tanda DM sehingga menyebabkan keterlambatan diagnosis, kurangnya kepatuhan dalam terapi insulin, dan belum matangnya sistem autoregulasi tubuh membuat anak lebih rentan terhadap KAD. 5 Studi pada tahun 2006 di 11 negara Asia dan Kawasan Pasifik Barat menyatakan insiden kejadian KAD pada pasien DM tipe-1 anak adalah 10 per 100 pasien pertahun. ${ }^{6}$ Di Indonesia, pada tahun 2017, 71\% pasien anak mengalami KAD sebagai presentasi klinis awal DM tipe- $1 .^{7}$

Pada pasien KAD dapat terjadi gangguan keseimbangan elektrolit tubuh, termasuk kalium. Terjadi penurunan kadar total kalium tubuh, walaupun sebenarnya dalam darah juga dapat terjadi hiperkalemia, normokalemia, maupun hipokalemia. Terjadinya defisiensi insulin, hiperglikemia, dan asidosis dapat menyebabkan peningkatan kadar kalium. Selain itu, diuresis osmotik, asupan makanan pada pasien yang kurang, dan muntah dapat menyebabkan penurunan kadar kalium. ${ }^{5,8-11}$

Abnormalitas kadar kalium, baik hiperkalemia maupun hipokalemia, dapat menyebabkan berbagai manifestasi patologis dalam tubuh berupa kelemahan, kebingungan, paralisis, dan pada hiperkalemia berat dapat terjadi abnormalitas ritme jantung yang fatal. Selain itu, hipokalemia dapat menyebabkan perubahan fungsi otot dan kardiovaskular, seperti kelemahan otot hingga kelumpuhan, mialgia, konstipasi, hiporefleksia, dan rabdomiolisis pada hipokalemia berat. ${ }^{12,13}$ Oleh karena itu, pada diagnosis KAD, selain pemeriksaan $\mathrm{pH}$ dan kadar bikarbonat untuk menentukan derajat penyakit, secara rutin penting juga dilakukan pemeriksaan kadar elektrolit, termasuk kalium.

Berdasarkan pemaparan di atas, diketahui bahwa KAD merupakan kondisi yang dapat mengancam jiwa, seringkali menyerang anak-anak, dan dapat menyebabkan abnormalitas kadar kalium yang dapat menyebabkan berbagai manifestasi patologis. Penelitian ini bertujuan untuk mengetahui hubungan antara derajat KAD dan kadar kalium. Dari hasil penelitian ini, diharapkan pemeriksaan kadar kalium dapat menjadi faktor prediktif terhadap derajat KAD sebelum tersedianya hasil pemeriksaan analisis gas darah.

\section{Metode}

Penelitian ini menggunakan rancangan studi analitik potong lintang. Data sekunder diperoleh dari data rekam medis pasien KAD anak (usia 0-18 tahun) di RSUP Dr. Hasan Sadikin Bandung selama periode Desember 2014 - Oktober 2019. Penelitian dilakukan pada bulan September - November 2019. Data rekam medis yang diambil, yaitu data usia, jenis kelamin, status gizi, derajat $\mathrm{KAD}$, faktor pencetus $\mathrm{KAD}$, regimen terapi insulin yang diberikan, serta data laboratorium (kadar $\mathrm{pH}$ darah, $\mathrm{HCO}_{3}$, GDS awal, natrium, dan kalium) sebelum pemberian terapi. Kriteria inklusi adalah pasien KAD anak di RSUP Dr. Hasan Sadikin Bandung periode Desember 2014-Oktober 2019. Adapun kriteria eksklusi adalah data hilang atau tidak lengkap, pasien dengan penyakit ginjal kronis (PGK) yang dapat memengaruhi kadar kalium pada tubuh, dan pasien dengan penyakit atau abnormalitas kalium bawaan, seperti sindrom Liddle, Bartter, Gitelman, familial hyperaldosteronism, pseudohypoaldosteronism, dan sebagainya.

Besar sampel ditentukan dengan rumus besar sampel penelitian analitik korelatif dan didapatkan minimal 38 sampel. ${ }^{14}$ Variabel bebas pada adalah derajat $\mathrm{KAD}$ yang dikategorikan menjadi ringan $(\mathrm{pH}$ darah $<7,3$ atau $\mathrm{HCO}_{3}<15 \mathrm{mEq} / \mathrm{L}$ ), sedang ( $\mathrm{pH}$ darah $<7,2$ atau $\mathrm{HCO}_{3}<10 \mathrm{mEq} / \mathrm{L}$ ), dan berat ( $\mathrm{pH}$ darah $<7,1$ atau $\mathrm{HCO}_{3}<5 \mathrm{mEq} / \mathrm{L}$ ). ${ }^{2}$ Variabel terikat adalah kadar kalium yang dikategorikan menjadi hipokalemia $(<3,5 \mathrm{mEq} / \mathrm{L})$, normokalemia $(3,5-5,5 \mathrm{mEq} / \mathrm{L})$, dan hiperkalemia $(>5,5 \mathrm{mEq} / \mathrm{L})$. Penelitian ini sudah mendapatkan pembebasan etik dari Komite Etik Penelitian Kesehatan Fakultas Kedokteran Universitas Padjadjaran dengan nomor 843/UN6.KEP/EC/2019.

Pengolahan dan analisis data dilakukan menggunakan program $I B M^{\circledR}$ SPSS Statistics 23. Uji hipotesis yang dilakukan adalah uji analisis korelasi Spearman untuk mengetahui hubungan antara derajat KAD dan kadar kalium. Nilai $p<0,05$ menunjukkan bahwa secara statistik hasil penelitian signifikan dan nilai koefisien 
Faisal dkk: Hubungan derajat KAD dengan kadar kalium

korelasi Spearman (r) menunjukkan kekuatan korelasi antara kedua variabel. Hasil penelitian disajikan dalam bentuk tabel.

\section{Hasil}

Jumlah pasien KAD anak di RSUP Dr. Hasan Sadikin Bandung periode Desember 2014 - Oktober 2019 sebanyak 48 pasien. Pasien yang memenuhi kriteria inklusi adalah 35, sedangkan 13 lainnya memiliki data hilang atau tidak lengkap. Karakteristik umum dan klinis pasien KAD anak di RSUP Dr. Hasan Sadikin Bandung tertera pada Tabel 1 dan 2.

Dari 35 pasien KAD, terdapat total 39 episode $\mathrm{KAD}$ (3 pasien mengalami kejadian KAD berulang). Sebanyak 22 pasien berjenis kelamin perempuan dan 13 laki-laki dengan rerata usia 11,2 $\pm 3,3$. Status gizi pasien terbanyak adalah pasien dengan gizi kurang berjumlah 18 (46,16\%) pasien.

Karakteristik klinis pasien berupa nilai laboratorium adalah sebagai berikut, $\mathrm{pH} 7,1 \pm 0,2, \mathrm{HCO}_{3} 6,5 \pm 3,9$, GDS awal 488,2 \pm 160 , natrium $133,5 \pm 4,9$, dan kalium $4,8 \pm 1,4$. Enam $(15,39 \%)$ pasien mengalami episode KAD ringan, $13(33,33 \%)$ sedang, dan $20(51,28 \%)$ berat. Faktor pencetus KAD adalah tidak atau pasien $(41,02 \%)$ yang belum diterapi, penghentian insulin $(23,08 \%)$, kontrol metabolik buruk (17,95\%), dan infeksi atau penyakit lainnya $(17,95 \%)$. Adapun 32 $(82,05 \%)$ pasien mendapat terapi insulin basal bolus dan $7(17,95 \%)$ pasien mendapat regimen terapi insulin split mix.

Tabel 1. Karakteristik umum pasien KAD anak

\begin{tabular}{lc}
\hline Karakteristik & Frekuensi \\
\hline Jenis kelamin $(\%)$ & \\
$\quad$ Perempuan & $22(62,86)$ \\
$\quad$ Laki-laki & $13(37,14)$ \\
Usia (tahun) (\%) & \\
$0-5$ & $3(7,69)$ \\
$6-12$ & $17(43,59)$ \\
$13-18$ & $19(48,72)$ \\
Rerata \pm SB & $11,2 \pm 3,3$ \\
Status gizi (\%) & \\
Baik & $16(41,02)$ \\
Kurang & $18(46,16)$ \\
Buruk & $4(10,26)$ \\
$\quad$ Lebih & $1(2,56)$ \\
\hline
\end{tabular}

Tabel 2. Karakteristik klinis pasien KAD anak

\begin{tabular}{|c|c|}
\hline Karakteristik & $\mathrm{n}=39$ \\
\hline \multicolumn{2}{|l|}{ Kadar pH darah } \\
\hline Rerata $\pm S B$ & $7,1 \pm 0,2$ \\
\hline Minimum & 6,79 \\
\hline Maksimum & 7,5 \\
\hline \multicolumn{2}{|l|}{ Kadar $\mathrm{HCO}_{3}$} \\
\hline Rerata \pm SB & $6,5 \pm 3,9$ \\
\hline Minimum & 1,7 \\
\hline Maksimum & 16,7 \\
\hline \multicolumn{2}{|l|}{ Gula darah sewaktu awal } \\
\hline Rerata $\pm S B$ & $488,2 \pm 160$ \\
\hline Minimum & 146 \\
\hline Maksimum & 844 \\
\hline \multicolumn{2}{|l|}{ Kadar natrium } \\
\hline Rerata $\pm S B$ & $133,5 \pm 4,9$ \\
\hline Minimum & 126 \\
\hline Maksimum & 146 \\
\hline \multicolumn{2}{|l|}{ Kadar kalium } \\
\hline Rerata $\pm S B$ & $4,8 \pm 1,4$ \\
\hline Minimum & 2,5 \\
\hline Maksimum & 9,1 \\
\hline \multicolumn{2}{|l|}{ Derajat KAD (\%) } \\
\hline Ringan & $6(15,39)$ \\
\hline Sedang & $13(33,33)$ \\
\hline Berat & $20(51,28)$ \\
\hline \multicolumn{2}{|l|}{ Regimen terapi insulin (\%) } \\
\hline Basal bolus & $32(82,05)$ \\
\hline Split mix & $7(17,95)$ \\
\hline \multicolumn{2}{|l|}{ Faktor pencetus KAD (\%) } \\
\hline Tidak/belum diterapi & $16(41,02)$ \\
\hline Penghentian insulin & $9(23,08)$ \\
\hline Kontrol metabolik buruk & $7(17,95)$ \\
\hline Infeksi atau penyakit lainnya & $7(17,95)$ \\
\hline
\end{tabular}

Tabel 3 menunjukkan adanya hubungan korelasi positif yang bermakna antara derajat KAD dan kadar kalium (nilai $\mathrm{p}=0,002$ ). Nilai koefisien korelasi Spearman (r) sebesar 0,471 menunjukkan korelasi sedang-lemah. ${ }^{15}$

\section{Pembahasan}

Pada penelitian ini, terdapat hubungan korelasi positif yang bermakna antara derajat KAD dan kadar kalium dengan kekuatan korelasi sedang-lemah (nilai $\mathrm{r}=0,471$, nilai $\mathrm{p}=0,002)$. Dapat dikatakan bahwa 
Faisal dkk: Hubungan derajat KAD dengan kadar kalium

Tabel 3. Tabulasi silang dan analisis korelasi Spearman antara derajat KAD dan kadar kalium

\begin{tabular}{|c|c|c|c|c|c|c|}
\hline \multirow{2}{*}{ Variabel } & \multicolumn{3}{|c|}{ Kadar kalium } & \multirow{2}{*}{$\begin{array}{l}\text { Total } \\
\text { (n) }\end{array}$} & \multirow{2}{*}{ Nilai r } & \multirow{2}{*}{ Nilai $\mathrm{p}$} \\
\hline & Hipokalemia & Normokalemia & Hiperkalemia & & & \\
\hline Derajat KAD & & & & & $0,471^{*}$ & 0,002 \\
\hline Ringan & 3 & 3 & 0 & 6 & & \\
\hline Sedang & 5 & 6 & 2 & 13 & & \\
\hline Berat & 1 & 12 & 7 & 20 & & \\
\hline Total (\%) & $9(23,08)$ & $21(53,84)$ & $9(23,08)$ & 39 & & \\
\hline
\end{tabular}

Keterangan: *korelasi signifikan pada level 0,01 (two-tailed)

semakin tinggi kadar kalium maka akan semakin berat derajat KAD. Sepengetahuan penulis, belum ada penelitian yang meneliti korelasi antara derajat KAD dan kadar kalium. Namun, penelitian oleh Fulop ${ }^{16}$ melaporkan adanya hubungan korelasi negatif yang bermakna antara kadar kalium dan kadar $\mathrm{pH}$ darah, menandakan semakin tinggi kadar kalium maka akan semakin berat derajat asidosis. Hal tersebut sejalan dengan hasil analisis pada penelitian ini.

Walaupun pada pasien KAD diperkirakan terjadi deplesi total kalium tubuh, pada pemeriksaan kadar kalium darah dapat juga terjadi hiperkalemia, normokalemia, maupun hipokalemia. Peningkatan kadar kalium pada KAD dapat terjadi karena beberapa hal. Defisiensi insulin menyebabkan pemasukan kalium ke dalam sel berkurang sehingga terjadi peningkatan kadar kalium ekstraseluler. Selain itu, asidosis metabolik menyebabkan ion hidrogen $\left(\mathrm{H}^{+}\right)$tinggi sehingga terjadi penurunan aktivitas pompa $\mathrm{Na}^{+}-\mathrm{K}^{+}$yang kemudian menyebabkan penurunan pemasukan kalium ke dalam sel dan meningkatkan konsentrasi kalium ekstraseluler. Peningkatan osmolaritas oleh hiperglikemia juga menyebabkan peningkatan konsentrasi kalium intraseluler sehingga menyebabkan difusi kalium ekstraseluler. $^{5,8,9}$ Sementara penurunan kadar kalium pada KAD dikaitkan dengan diuresis osmotik, asupan makanan kurang, dan muntah. ${ }^{10,11}$

Mayoritas pasien penelitian ini adalah perempuan $(62,86 \%)$ dibandingkan laki-laki $(37,14 \%)$. Tiga pasien perempuan mengalami episode KAD berulang. Hal ini serupa dengan penelitian $\mathrm{Aji}^{17}$ yang melaporkan persentase pasien $\mathrm{KAD}$ anak perempuan $63,2 \%$ dan laki-laki 36,8\% di Malang. Sementara Rochmah dkk ${ }^{18}$ melaporkan persentase pasien perempuan $69 \%$ di Surabaya. Kelompok usia terbanyak adalah kelompok usia 13-18 tahun (48,72\%) dan kelompok usia 6-12 tahun $(43,59 \%)$. Hal ini menandakan mayoritas pasien perempuan dan remaja pada KAD. International Society for Pediatric and Adolescent Diabetes (ISPAD) menyatakan bahwa salah satu faktor risiko KAD adalah pasien peripubertal dan remaja perempuan. ${ }^{2}$ Namun, penelitian oleh Listianingrum $\mathrm{dkk}^{19}$ melaporkan bahwa tidak ada hubungan antara jenis kelamin perempuan dan insidensi KAD.

Faktor pencetus tersering adalah tidak atau belum diterapinya pasien $(41,02 \%)$, menandakan KAD sebagai presentasi klinis awal DM tipe-1. Sementara faktor pencetus lainnya adalah penghentian insulin (23,08\%), kontrol metabolik buruk (17,95\%), dan infeksi atau penyakit lainnya (17,95\%). Penelitian di RSCM Jakarta pada tahun 2002 melaporkan 66\% pasien anak pertama kali datang dengan KAD sebelum didiagnosis DM tipe- $1 .{ }^{20}$

Pada pasien KAD seringkali ditemukan abnormalitas kadar kalium. Pada penelitian ini ditemukan proporsi yang serupa antara hipokalemia dan hiperkalemia pada pasien (keduanya memiliki persentase $23,08 \%$ ). Hal ini berbeda dengan penelitianpenelitian terdahulu hingga studi pada tahun 2018 yang secara konsisten melaporkan bahwa pada KAD, kadar kalium seringkali ditemukan normokalemia atau hiperkalemia, sedangkan hipokalemia terjadi hanya pada sebagian kecil (5-15\%) pasien. ${ }^{10,21,22}$

Dibutuhkan penanganan yang cepat pada KAD untuk menurunkan kemungkinan komplikasi lebih lanjut. Maka dari itu, penentuan diagnosis dan derajat KAD juga harus dilakukan dengan cepat. Pemeriksaan elektrolit darah dapat dilakukan dengan sederhana dan cepat. Hasil pemeriksaan elektrolit, khususnya kadar kalium, diharapkan dapat dijadikan faktor prediktif terhadap derajat KAD dan acuan untuk terapi awal pasien KAD.

\section{Kesimpulan}

Berdasarkan hasil penelitian ini belum dapat disimpulkan hubungan antara KAD dengan kalium 
mengingat sampel yang belum memadai dan hasil uji yang masih lemah. Namun, pada KAD, sebaiknya selalu memeriksa kadar elektrolit, khususnya kalium karena mungkin dapat terjadi hipo, hiper atau normokalemi. Keterbatasan pada penelitian ini adalah jumlah sampel yang masih merupakan jumlah minimal. Disarankan dilakukan perbaikan pencatatan data rekam medis di RSUP Dr. Hasan Sadikin agar data yang tersedia lengkap sehingga tidak banyak sampel yang tereksklusi, kemudian penelitian berikutnya dapat menggunakan jumlah sampel lebih banyak agar analisis yang didapatkan lebih akurat.

\section{Daftar pustaka}

1. Powers AC. Diabetes Mellitus. Dalam: Jameson JL, penyunting. Harrison's endocrinology. Edisi ke-3. McGrawHill; 2013.h.261-307.

2. Wolfsdorf JI, Glaser N, Agus M, Fritsch M, Hanas R, Rewers A, dkk. ISPAD Clinical Practice Consensus Guidelines 2018: Diabetic ketoacidosis and the hyperglycemic hyperosmolar state. Pediatr Diabetes 2018;19:155-77.

3. UKK Endokrinologi Anak dan Remaja Ikatan Dokter Anak Indonesia. Konsensus Nasional Pengelolaan Diabetes Mellitus Tipe I. Badan Penerbit Ikatan Dokter Anak Indonesia; 2015.

4. Santoso F, Soewondo P, Widyahening IS, Wisnu W. Faktorfaktor yang mempengaruhi ketoasidosis diabetik berulang: laporan kasus berbasis bukti. J Dr Kel Indones 2016;2:20-5.

5. Wolfsdorf J, Glaser N, Sperling MA. Diabetic ketoacidosis in infants, children, and adolescents. Diabetes Care 2006;29:1150-9.

6. Craig ME, Jones TW, Silink M, Ping YJ. Diabetes care, glycemic control, and complications in children with type 1 diabetes from Asia and the Western Pacific Region. J Diabetes Complications 2007;21:280-7.

7. Pulungan AB, Annisa D, Imada S. Diabetes Melitus Tipe-1 pada Anak : Situasi di Indonesia dan Tata Laksana. Sari Pediatri 2019;20:392-400.

8. Hall JE. Insulin, glucagon, and diabetes mellitus. Dalam: Hall JE, penyunting. Guyton, and Hall Textbook of Medical Physiology. Edisi ke-13. Elsevier; 2016.h.983-99.
9. Usman A. Initial potassium replacement in diabetic ketoacidosis: the unnoticed area of gap. Front Endocrinol (Lausanne) 2018;9:1-3.

10. Arora S, Cheng D, Wyler B, Menchine M. Prevalence of hypokalemia in ED patients with diabetic ketoacidosis. Am J Emerg Med 2012;30:481-4.

11. Kamel KS, Schreiber M, Carlotti APCP, Halperin ML. Approach to the treatment of diabetic ketoacidosis. Am J Kidney Dis 2016;68:967-72.

12. Pohl HR, Wheeler JS, Murray HE. Sodium and potassium in health and disease - interrelations between essential metal ions and human diseases. Dordrecht: Springer Netherlands; 2013.h.29-47.

13. Daly K, Farrington E. Hypokalemia and hyperkalemia in infants and children: pathophysiology and treatment. J Pediatr Heal Care 2013;27:486-96.

14. Dahlan MS. Statistik untuk kedokteran dan kesehatan: deskriptif, bivariat, dan multivariat. Edisi ke-6. Jakarta: Epidemiologi Indonesia; 2014.

15. Chan YH. Biostatistics 104: correlational analysis. Singapore Med J 2003;44:614-9.

16. Fulop M. Hyperkalemia in diabetic ketoacidosis. Am J Med Sci 1990;299:164-9.

17. Aji CH. Gambaran klinis ketoasidosis diabetikum anak. J Kedokt Brawijaya 2012;27:107-10.

18. Rochmah N, Faizi M, Harjantien N. Diabetic ketoacidosis in children: an 11-year retrospective in Surabaya, Indonesia. Paediatr Indones 2015;55:40-3.

19. Listianingrum, Patria SY, Wibowo T. Predictive factors of ketoacidosis in type 1 diabetes mellitus. Paediatr Indones 2019;59:169-74.

20. Pulungan AB, Mansyoer R, Batubara JR, Tridjaja B. Gambaran klinis dan laboratoris diabetes mellitus tipe-1 pada anak saat pertama kali datang ke Bagian IKA-RSCM Jakarta. Sari Pediatri 2002;4:26-30.

21. Kanwal SK, Bando A, Kumar V. Clinical Profile of Diabetic Ketoacidosis in Indian Children. Indian J Pediatr 2012;79: 901-4.

22. Del Pozo P, Aránguiz D, Córdova G, Scheu C, Valle P, Cerda J, dkk. Clinical profile of children with diabetic ketoacidosis in fifteen years of management in a Critical Care Unit. Rev Chil Pediatría 2018;89:491-8. 